\title{
Invited Symposium Long-term memories: How durable, and how enduring?
}

\section{Replicative, constructive, and reconstructive aspects of memory: Implications for human and animal research}

\author{
HARRY P. BAHRICK \\ Ohio Wesleyan University, Delaware, Ohio
}

I am honored to be included in a symposium exploring the physiology of memory. As the only nonphysiologist in this group, I know that you do not expect me to contribute data based upon neurological interventions. I won't surprise you. I am not certain I could differentiate between a human brain and a monkey brain, but such discrimination failure does not prevent me from taking part in the dialogue between cognitive and physiological psychologists. I believe that this dialogue is important. It seems to me that much of the time our respective explorations are parallel rather than interactive, but I do not find this alarming, and I am confident that in the long run our respective findings will have a profound impact on each other's work. In the meantime, some discussion of why this does not always appear to be the case is appropriate, and I am going to examine the relevant issues historically.

It is true that cognitive psychologists frequently cite physiological findings to support their conceptualizations of memory, but most of the time this is done post hoc, and I agree with Skinner's (1953) view that such physiologizing improves only the surface credibility without affecting the validity of cognitive models. Physiological psychologists nearly always use behavioral tests to answer their questions about the effect of neurological interventions, but it seems to me that currently these questions relate only tangentially to some of the key questions cognitive psychologists are most concerned with. During the 1940s and 1950s, the efforts of physiological and behavioral psychologists were more closely linked. Learn-

This contribution was presented as part of an invited symposium at the Midwestern Psychological Association meetings, Chicago, May 1984, entitled "Long term memory: How durable, and how enduring?" H. P. Bahrick's mailing address is: Department of Psychology, Ohio Wesleyan University, Delaware, OH 43015. ing and memory were viewed as the strengthening and the persistence of habits or response tendencies, and the efforts of physiological psychologists were directed toward finding the locus of engrams representing these changes. Not only physiological research, but also behaviorally oriented learning and memory research made extensive use of animal subjects. This was appropriate within the context of a reductionist paradigm which assumed that the fundamental process of learning was association, and that this process could be investigated conveniently in animals. The era dominated by rat psychology came to an end in the 1960s, when reductionist assumptions were effectively challenged. Cognitive psychologists began to dominate learning and memory research. They viewed learning and memory primarily in terms of organizational processes, not in terms of strengthening habits or response tendencies. Memory research began to focus on the study of encoding, transforming, and retrieving information. This cognitive emphasis was coupled witt a diminution in the use of animals as subjects. The tudy of animal behavior continues on a more modest scale, but this research is ecologically oriented and conceived as a contribution to comparative psychology, rather than a direct attempt to shed light on the functioning of the human memory system. There are compelling reasons for the diminished use of animals as subjects in cognitive memory research. Although it can be argued that organizational processes characterize the functioning of both human and animal memory, recent research has focused upon linguistic organization which is distinctively human. The shift in emphasis from animal to human subjects is accommodated more easily by cognitive scientists than by neuroscientists. Most neurological interventions are performed with animals, since such interventions are appropriate for humans only to the extent to which 
they alleviate existing injury, disease, or defect. Thus, physiologically oriented memory research based upon human subjects is limited to clinical cases, and interventive research based upon animal subjects may not be able to address key questions regarding the nature of organizational processes.

In spite of these constraints, physiological psychologists have been successful in attacking certain important issues of cognitive processing by means of neurological interventions with animals. Questions regarding the role of short-term dynamic processing in establishing semipermanent memories are a good example. By using electroconvulsive shock, antibiotic treatment, or $\mathrm{CO}_{2}$ treatment to interfere with dynamic processing, newly learned habits were shown to be lost, only to be recovered at a later time following peptide treatments, saline flushing, or other neurological interventions (D. R. Meyer, 1972). These findings support the significance of the storageretrieval distinction, a focal issue of cognitive research. Equally impressive are the demonstrations that the retrieval of animal memories spared after intervention depends upon the specificity of reinstatement of both external (LeVere \& Davis, 1977; LeVere, Davis, \& Fontaine, 1978) and internal (Mactutus, Ferek, \& Riccio, 1980; Mactutus, McCutcheon, \& Riccio, 1980) conditions present at the time of acquisition. This research closely parallels the work on encoding specificity and state dependence, which have been prominent concerns of cognitive theorists. Another current concern to which I will return later deals with the longevity of memory traces, and the Meyers (D. R. Meyer \& P. M. Meyer, 1984) have documented the virtual indestructibility of memories that endure throughout the lifetime of animals, and are rendered only temporarily nonretrievable by extirpation procedures.

My main concern, however, is with issues regarding the nature of memory which cannot easily be explored with animals subjects, and which have begun to dominate the development of cognitive theory.

\section{Replicative vs. Constructive Views of Memory- A Current Issue in Historical Perspective}

In 1690 , John Locke $(1690 / 1959)$ distinguished between sensation and reflection as sources of ideasthe units of mental content. Reflections consist of ideas about ideas and constitute an inner sense of knowledge which adds to and modifies the simple sensory content of the mind as generated by the world of objects. Locke inferred that the content of a child's mind was largely object-determined and represented a succession of simple ideas, whereas the mental content of an adult involved more complex ideas greatly modified by a history of reflection. During the 100-year history of experimental psychology, the exploration of memory has been polarized at one or the other extreme of the Lockian di- mension, without achieving the continuity and integration suggested by Locke's analysis. Early psychologists found it far easier to explore mental content closely linked to sensory stimuli than mental content that is sui generis, that is, the result of reflective processes. This difference is apparent in the early analysis of conscious content into sensory elements and in the early history of memory research. The Ebbinghaus tradition is based upon the study of associations among target items presented by an experimenter, and the tasks provide minimal opportunity for examining reflective content. This was not done because Ebbinghaus denied the existence of internally generated memory content-for example, dreams or phantasy, or the importance of modifications of sensory content on the basis of existing knowledge-but because he believed it methodologically expedient to deal with content under the control of the experimenter and to separate the associative processes from the interpretive ones. He chose to study nonsense syllables because he correctly believed that the use of meaningless material would reduce the interpretive processes that inevitably affect memory of more meaningful material (DiSibio, 1982). For the purpose of this discussion, I will differentiate between replicative, constructive, and reconstructive aspects of memory, and I will base my distinction on the retrieved content rather than on the cognitive processes by which information is encoded, stored, or retrieved. By replicative aspects, I refer to content that closely matches the target material presented; by constructive aspects, I refer to modifications of the presented content that occur immediately or within a few seconds following presentation; and by reconstructive aspects, I refer to modifications that occur over a longer period, for example, hours, days, or years. It is obvious that the content retrieved at a given time may reflect all of these aspects. Some of the retrieved content may match the originally presented content, but other portions may have been modified immediately or at some later time. Furthermore, it is clear that the constraints imposed by a given memory task will greatly influence the opportunities to observe constructive or reconstructive content. Thus, remembering the correct turn in a maze or the correct response in a two-choice discrimination task provides minimal opportunity for observing a variety of modifications of content, whereas the task of recalling an earlier conversation or a story or of redrawing a complex visual display provides ample opportunities for observing constructive content.

I have based the distinction between replicative and constructive aspects of memory on the retrieved content, and not on the cognitive processes that yield that content. It is clear that constructive content reflects constructive processing, but it is not clear whether replicated content is based only upon rep- 
licative processing, that is, processing that preserves the sensory content of the material, or whether it may also involve interpretive and elaborative modifications that are obscured by the nature of the task. Observations in memory experiments are limited to retrieved content, and inferences regarding the nature of processing must be based upon that content. The results of memory research in the Ebbinghaus tradition do not demonstrate that performance on meaningless material is unaffected by internal constructive processes; they indicate only that good statistical predictions of replicative performance is possible for such tasks on the basis of the manipulated stimulus conditions, without the need to invoke assumptions about constructive or reconstructive processing. The success of memory research in achieving these limited objectives led to an unrealistic assessment of the state of the art and to simplistic views of memory, in keeping with the assumptions of the dominant behavioristic and reductionist paradigm. The prevailing view was that the content stored for more meaningful memory tasks was also largely replicative and would eventually be accounted for on the basis of principles deduced from the study of memory for meaningless material. This view made the study of memory for meaningful material appear unscientific and unnecessary.

The reductionist view was challenged early on by Gestalt psychologists (Wulf, 1922) and pioneer cognitive psychologists (Tolman, 1949). They argued that learning and memory were inherently organizational processes, but that these processes were obscured because the common laboratory tasks precluded relevant observations. Their assertions were soon documented by research that confirmed that individuals selectively remember content that relates to their motives (Zeigarnik, 1927), agrees with their attitudes (Edwards, 1941, 1942), and is modified by schema with which they are familiar (Bartlett, 1932). The effective challenge to the replicative view of memory processing became overwhelming as soon as memory research concentrated on meaningful verbal content. Individuals asked to recall prose passages or stories recall these in their own words, generally preserving the so-called deep structure or meaning, but substantially altering the specific word sequence, that is, the surface structure. The performance is constructive in that the stored content does not replicate the presented content; rather, the stored content is modified in accordance with the semantic organization available in the memory store. It seems obvious, however, that the same task of repeating a prose passage, given to individuals who are not conversant with the language in which the passage is presented would yield much poorer performance, and that the reported content would closely resemble the surface structure of the stimulus material. Such a demon- stration indicates that performance is constructive and superior when it is based upon extensive, relevant information available to the individual, and that when such information is absent, performance is poorer and more replicative, that is, more closely tied to the stimuli presented (Chiesi, Spilich, \& Voss, 1979). Available knowledge improves performance and determines the amount of constructive processing.

Research based upon the levels-of-processing framework (Craik \& Lockhart, 1972) demonstrates further that the constructive enhancement of performance depends upon whether the task permits the individual to process information in relation to the available semantic organization. If individuals are deterred from such processing by means of an orienting task that forces them to respond to nonsemantic characteristics of the stimulus material, their performance is poorer and less constructive, for example, the order of recall is less modified by the available semantic knowledge.

Cofer (1973) discusses constructive memory processing as an essential aspect of adaptation to a natural environment in which circumstances are never exactly the same as those encountered at an earlier time. The capacity to modify performance in accordance with available knowledge lends adaptive signficance to constructive memory and illustrates that memory, inference, and problem solving are often confounded rather than being distinct processes (Cofer, 1976). It was the anticipation of this methodological problem which led Ebbinghaus to attempt a separation by investigating content that provides minimal opportunity for constructive processing.

\section{Constructive vs. Reconstructive Content}

The contention that memory performance reflects not only progressive losses of information, but also progressive modifications is certainly not new. This conception of memory is central to psychoanalytic theory, and it is also central to the work of Bartlett (1932) and the Gestalt psychologists who introduced the concepts of sharpening, leveling, and assimilation (Wulf, 1922). Such findings have led to the contention that all memory processes are reconstructive in the sense that each attempt at retrieval of an earlier memory constitutes a process in which the target content is modified as a result of interactions with other information in the memory store. Neisser's analysis of John Dean's Watergate testimony (Neisser, 1981) demonstrates that autobiographical memory content can be so strongly altered by existing schemas and expectations that the reconstructed content may bear little surface resemblance to the objective content it purports to reflect, and only preserves some general, underlying themes, which Neisser calls rhepisodic, because they are common to a series of repeated, re- 
lated episodes. Neisser (1984) states the issue very clearly in contrasting the reappearance hypothesis with the reconstruction hypothesis. He contends that remembering is like problem solving, rather than like reproduction, and that constructive recall is the rule, and literal recall is the exception. He cites evidence regarding memory for sentences (Sachs, 1967), event descriptions (Bransford \& Franks, 1971), stories (Mandler \& Johnson, 1977), scripts (Bower, Black, \& Turner, 1979; Nelson \& Gruendel, 1981), crimes witnessed (Loftus, 1979), oral poetry (Lord, 1960), and oral history (d'Azevedo, 1962) to document the case. There can be no argument about the validity of the evidence he cites for the existence of reconstructive memory processes. However, there is substantial basis for argument about the relevance of this evidence to all, or most, acts of remembering. There is no indication of reconstructive change in remembering one's name, the answer to simple arithmetic problems, the meanings of common words in our native language, and thousands of other overlearned facts, rules, or meanings that constitute much of our general knowledge. These instances of literal recall are not the exception; they are the rule for overlearned memory content.

Reconstructive changes have been observed primarily in regard to autobiographical or other episodic memory content strongly tied to emotional or motivational processes and content that provides few opportunities for reality monitoring. Progressive modifications have not been reported for memory content that is overlearned or motivationally neutral, or for which there are readily available monitoring opportunities. In their excellent review of schematic memory theory, Alba and Hasher (1983) conclude that reconstructive processes are optional and not likely to be involved in the retrieval of general knowledge. Even when recall involves inference and problem solving, the reconstruction of content often is based upon effective use of overlearned, replicated aspects of memory content. Thus, the individual attempting to reconstruct details of episodic memory regarding the arrangement of rooms and furniture in a particular house will rely on general knowledge about houses to aid in the retrieval of missing details.

\section{Implications for the Future of Memory Research}

Research attempting to demonstrate that all memory content is constructively or reconstructively modified is likely to be no more useful or successful than earlier efforts designed to demonstrate that all memory content is the result of a gradual process of strengthening individual associations. Rather, the thrust of our efforts must be in the direction of expanding and improving methodology so as to be able to investigate content that cannot be adequately explored at the moment. Memory content includes not only information presented by an experimenter in the laboratory, but also all experiences of individuals, including their dreams, fantasies, and other cognitive processes. In the past, investigators have excluded most autobiographical content as well as virtually all educational content because available methods were suitable only for content under direct control of the experimenter. The traditional methods applied to episodic content learned in the laboratory generated reliable findings, but they led to unrealistically simplistic models of memory which overemphasized the replicative aspects of memory. Greater ecological relevance can be achieved only as methods that are able to overcome these problems are developed. Thus, REM recording (Aserinsky \& Kleitman, 1953) opened opportunities for investigating memory of dreams; Marcia Johnson's (Johnson \& Kahan, in press; Johnson \& Raye, 1981) methods for investigating reality monitoring make it possible to determine the accuracy of discriminating memory content that is self-generated from memory content that is experimenter supplied, and my own efforts, based on the use of multiple regression analysis (H. P. Bahrick, 1983, 1984; H. P. Bahrick, P. O. Bahrick, \& Wittlinger, 1975), make it possible to investigate semantic content acquired ecologically and tested over very long time periods.

It seems to me that the lessons to be learned from our past are very clear. We can answer questions only to the extent to which the available methods permit, and we must avoid overgeneralizing conclusions reached on the basis of having examined restricted memory content. New methods generally open new content areas without becoming panaceas. Progress does not occur by proclaiming generalizations about memory that extend far beyond the conditions of empirical validation, but by systematically exploring questions that yield to the available methods and by developing new methods suitable for the investigation of content which cannot be dealt with adequately with existing methods (H. P. Bahrick, 1979). It is clear that future memory research will not again be limited to laboratory tasks or to episodic content tested over short time intervals. Rather, research will cover the entire life span and will include autobiographical content and content that is emotionally and motivationally significant. The pace of this evolution will be determined by the development of suitable methods. The next stage of research cannot be limited to demonstrating the existence of constructive and reconstructive processing for various types of memory content. Rather, it must aim to establish an extensive data base suitable for obtaining normative information regarding the extent of constructive and reconstructive change typical for various types of memory content.

What does all of this have to do with the relation between memory research conducted by physiological psychologists and that conducted by cognitive 
psychologist? The available methods are not equally suitable for answering the same questions about human and animal memory. Rather, research based upon neurological interventions with animals is better able to answer certain important questions, but it cannot at the moment deal with other questions. Animal research is particularly suitable for investigating the fate of memory content longitudinally over the entire life span (D. R. Meyer, 1972), for determining the effects of specific previous content on the retention or acquisition of subsequently acquired content, and for determining the effects of a variety of conditions of acquisition, intervention, and retrieval, or the role played by various neural centers. Questions not suitable for animal research concern content that is species specific, for example, linguistically encoded knowledge, as well as constructive and reconstructive changes of autobiographical content not readily revealed by animals. The relevant data for the latter type of research will be obtained by cognitive psychologists and physiological psychologists working with human patients.

These latter types of inquiry may command center stage for the moment because the research is likely to yield knowledge that is sorely needed by educators, clinicians, jurists, and other professionals who need to understand human memory in naturalistic settings. It would be a mistake, however, to believe that memory research based upon the Ebbinghaus traditions, or research based upon neurological interventions with animals, is invalid, obsolete, or trivial. The human mind stores a great variety of information. The task at hand is to explore how various types of information are acquired, maintained, modified, or lost. Limiting assumptions regarding the processes involved are inappropriate at this stage of our knowledge, no matter how parsimoniously attractive these assumptions seem to be. Memory research must continue to be a pluralistic, pragmatic attack on a variety of problems amenable to the available methods. Research will focus on somewhat different questions for those who practice neurological interventions with animals, those who investigate the effects of neurological damage in humans, those who investigate long-term autobiographical memory content, and those who investigate the preservation of educational content. Such differences of emphasis are not a weakness, but a potential strength of our developing science, because they give a measure of assurance that future integrative models of memory will be more realistic then the artifactually simplistic earlier ones.

\section{REFERENCES}

Alba, J. W., \& Hasher, L. (1983). Is memory schematic? Psychological Bulletin, 93, 203-231.

Aserinsky, E., \& KLEITMAN, N. 1953). Regularly occurring periods of eye motility, and concomitant phenomena, during sleep. Science, 118, 273-274.
BAHRICK, H. P. (1979). Broader methods and narrower theories for memory research: Comments on the papers by Eysenck and Cermak. In L. Cermak \& F. I. M. Craik (Eds.), Levels of processing in human memory. Hillsdale, NJ: Erlbaum.

BAHRICK, H. P. (1983). The cognitive map of a city-50 years of learning and memory. In G. H. Bower (Ed.), The psychology of learning and motivation: Advances in research and theory (Vol. 17). New York: Academic Press.

BAHRick, H. P. (1984). Semantic memory content in permastore50 years of memory for Spanish learned in school. Journal of Experimental Psychology: General, 113, 1-31.

Bahrick, H. P., Bahrick, P. O., \& Wittlinger, R. P. (1975). Fifty years of memories for names and faces: A cross-sectional approach. Journal of Experimental Psychology: General, 104, 54-75.

Bartlett, F. C. (1932). Remembering. Cambridge, England: Cambridge University Press.

Bower, G. H., Black, J. B., \& Turner, T. J. (1979). Scripts in memory for text. Cognitive Psychology, 11, 177-220.

Bransford, J. D., \& Franks, J. J. (1971). The abstraction of linguistic ideas. Cognitive Psychology, 2, 331-350.

Chiesi, H. L., Spilich, G. J., \& Voss, J. F. (1979). Acquisition of domain-related information in relation to high and low domain knowledge. Journal of Verbal Learning and Verbal Behavior, 18, 257-273.

Cofer, C. N. (1973). Constructive processes in memory. American Scientist, 61, 537-543.

Cofer, C. N. (Ed.) (1976). The structure of human memory. San Francisco: Freeman.

Craik, F. I. M., \& LockharT, R. S. (1972). Levels of processing: A framework for memory research. Journal of Verbal Learning and Verbal behavior, 11, 671-684.

D'Azeve Do, W. L. (1962). Uses of the past in Gola discourse. Journal of African History, 3, 11-34.

DiSibio, M. (1982). Memory for connected discourse: A constructivist view. Review of Educational Research, 52, No. 2, 149-174.

EDwards, A. L. (1941). Political frames of reference as a factor influencing recognizing. Journal of Abnormal and Social Psychology, 36, 34-61.

EDwards, A. L. (1942). The retention of affective experiencesA criticism and restatement of the problem. Psychological Review, 49, 43-55.

Johnson, M. K., \& Kahan, T. L. (in press). Dreams and reality monitoring. Journal of Experimental Psychology: General.

JoHnson, M. K., \& RAYE, C. L. (1981). Reality monitoring. Psychological Review, 88, 67-85.

LEVERE, T. E., \& Davis, N. (1977). Recovery of function after brain damage: The motivational specificity of spared neural traces. Experimental Neurology, 57, 883-898.

LeVere, T. E., Davis, N., \& Fontaine, C. W. (1978). Recovery of function after brain damage: The extrinsic stimulus specificity of spared neural traces. Brain Research Bulletin, 3, 29-35.

LOcke, J. (1959). An essay concerning human understanding (A. C. Fraser, Ed.). New York: Dover Press. (Original work published, 1690)

LoFTus, E. F. (1979). Eyewitness testimony. Cambridge, MA: Harvard University press.

LonD, A. B. (1960). The singer of tales. Cambridge, MA: Harvard University Press.

Mactutus, C. F., FereK, J. M., \& Riccio, D. C. (1980). Amnesia induced by hypothermia: An unusually profound, yet reversible memory loss. Behavioral and Neural Biology, 30, 260-277.

Mactutus, C. F., McCutcheon, K., \& Riccio, D. C. (1980). Body temperature cues as contextual stimuli: Modulation of hypothermia-induced retrograde amnesia. Physiology \& Behavior, 25, 875-883.

Mandler, J. M., \& Johnson, N. S. (1977). Remembrance of things parsed: Story structure and recall. Cognitive Psychology, 9, 111-151.

MEYER, D. R. (1972). Access to engrams. American Psychologist, 27, 124-133. 
Meyer, D. R., \& Meyer, P. M. (1984). On recoveries from impairments of remembering. In L. Squire \& N. Butters (Eds.), Neuropsychology of memory. New York: Guilford Press.

Neisser, U. (1981). John Dean's memory: A case study. Cognition, 9, 1-22.

Neisser, U. (1984). Interpreting Harry Bahrick's discovery: What confers immunity against forgetting. Journal of Experimental Psychology: General, 113, 32-35.

Nelson, K., \& GRUEnDEL, J. (1981). Generalized event representations: Basic building blocks of cognitive development. In M. E. Lamb \& A. L. Brown (Eds.), Advances in developmental psychology (Vol. 1). Hillsdale, NJ: Erlbaum.

SACHS, J. S. (1967). Recognition memory for syntactic and semantic aspects of connected discourse. Perception \& Psychophysics, 2 437-442.

SkinNe R, B. F. (1953). Science and human behavior. New York: MacMillan.

Tolman, E. C. (1949). There is more than one kind of learning. Psychological Review, 56, 144-156.

Wulf, F. (1922). Über die Veranderung von Vorstellungen (Gedaechtnis und Gestalt). Psychologische Forschung, I, 333-373.

ZEIGARNIK, B. (1927). Das Behalten erledigter und unerledigter Handlungen. Psychologische Forschung, 9, 1-85.

(Manuscript accepted for publication May 25, 1984.) 